\title{
AÇÃO DA TERAPIA FOTODINÂMICA EM Klebsiella pneumoniae (ATCC 4352) UTILIZANDO MODELO DE INFECÇÃO Galleria mellonella
}

\author{
Raquel Teles de Menezes ${ }^{1}$ \\ Lívia Mara Alves Figueiredo² \\ Mirian Marcolan de Mello $^{3}$
}

\begin{abstract}
Resumo: Klebsiella pneumoniae é um dos patógenos que possui grande resistência a vários antimicrobianos. A Terapia Fotodinâmica Antimicrobiana (PDT) vem sendo estudada como novo recurso no combate à resistência bacteriana. Objetivo: Avaliar a ação antimicrobiana da PDT em $\underline{\text { K. pneumoniae }}$ utilizando como modelo de infecção in vivo Galleria mellonella. Métodos: Foram inoculados $10 \mu \mathrm{L}$ da suspensão padronizada de $\underline{\text {. }}$ pneumoniae ATCC 4352 na última proleg esquerda de cada larva selecionada de G. mellonella. Decorridos 30 minutos, as larvas foram submetidas a PDT, com o uso do fotossensibilizador Azul de metileno e Laser de Arseneto de Gálio Alumínio. Passadas 24h, por sete dias o número de lagartas mortas foi anotado para a realização da curva de sobrevivência. Resultados: A PDT contribuiu para melhora da sobrevida das larvas, porém sem apresentar diferença estatística significante. Conclusão: A PDT apresentou atividade antimicrobiana contra a cepa de $\underline{\text { K}}$. pneumoniae ATCC 4352.

Palavras-chave: Klebsiella pneumoniae; Terapia fotodinâmica; Galleria mellonella.
\end{abstract}

\footnotetext{
${ }^{1}$ Biomedicina/Universidade Paulista, Brasil, E-mail: raquelmenezes93@gmail.com.

2 UNESP-Campus de São José dos Campos, Brasil. E-mail: livia.figueiredo@ict.unesp.br.

3 Universidade Paulista, Brasil. E-mail: marcolanmirian@yahoo.com.br.
} 